further strengthened in my opinion by another case, which, although it occurred to me some time since, is still fresh in $\mathrm{my}$ memory. I was called to see a gentleman with a swollen testis, and excessive uxinary irritation; the case was supposed to be one of hydrocele by one surgeon, of stone by another. On sounding, no stone was discoverable, and I suggested scrofulous abscess in the prostate, as the cause. He died; worn out much in the same manner as our unfortunate patient, and the examination after death proved the accuracy of the diagnosis.

In regard to the case before us, I must remark to you that at any rate the signs of the disease alluded to are unquestionably equivocal, and that a similar train of symptoms may arise from other causes than the one in question; nay, that you may have almost all the symptoms present, notwithstanding no disease at all exist at the neck of the bladder, for there is no doubt that excessive irritation of the bladder, accompanied by pain in micturition, bloody, and even purulent urine, may result from disease of the kidneys, and that some of these symptoms may depend on an increase in the acid constituents of the urine.

The deposit of scrofulous tubercles in the prostate is decidedly rare, and is found to occur usually in cases where tuberculosis prevails throughout the urinary and genital system. I have, in the article "Prostate" of the Cyclopædia of Anatomy, collected a few cases from different authorities, and have mentioned one in which as many as thirty small abscesses, and as many crude tubercles, existed in the prostate; the case is related by Lallemand.

$\mathrm{It}_{\mathrm{t}}$ is impossible by any signs with which we are acquainted to recognise the disease before the tubercles have advanced to softening and suppuration, and therefore it is useless to say anything about the treatment in the early stage; and even in the advanced stage of the disease, as in the case before us, a palliative mode of treatment, by sedatives, to lull the pain, and the employment of means calculated to sustain the ceneral health, are alone calculated to benefit the patient. You will find, however, in this instance, that various medicines were had recourse to, but when the case became fairly made out, I contented myself with the endeavour to lull the patient's sufferings, and to support the general health.

The post-mortem examination of the case is interesting, as exemplifying a mode of termination of such cases which is by no means common; thus you perceive that the immediate cause of death was peritonitis from the bursting of an abscess from the pelvis, through the peritonæum. In the last volume of the Medico-Chirurgical Transactions a case is recorded of a large abscess which formed in one of the vesiculæ seminales and made its way into the peritonæum, thus producing death by inducing subacute peritonitis; and, to a certain extent, there is an analogy between that case and the one under consideration.

\section{ON THE BEST PREPARATION OF ARSENIC FOR INTERNAL ADMINISTRATION,}

AND ON THE CHEMICAL COMPOSITION OF FOWLER'S SOLUTTON. BY LLOYD BULLOCK, Esq.

Durivg several years past, I have from time to time been asked by practitioners, both in town and country, whether no better and more convenient form of arsenic could be recommended for internal administration than the liquor arsenicalis of the Pharmacopoia. It appears to be the opinion of many who employ arsenic, either as an anti-periodic, or against skin diseases, that the officinal preparation is uncertain in its action--what is usually deemed a small dose in some cases acting with violence, whilst, in others, large doses produce but little effect. This may doubtless, in a great measure, be referred rather to peculiarities of constitution in the patient than to differences in the preparation. Nevertheless, the mode of preparing the liquor arsenicalis adopted by all the colleges belongs to a period antecedent to the present state of chemistry, which demands, in all cases, precision, and the rejection of every process either vague in itself, or admitting the possibility of failure to obtain the intended result. In the instance of the solution of a metallic salt, the maintenance of a certain standard strength being always the desired object, it is certainly always desirable, if possible, first to obtain the salt in a crystaline form, and then, being assured of its purity, both by its chemical and physical characters, to dissolve it in an exact amount in the necessary proportion of menstruum. On this principle I have for several years recommended the employment of the arseniate of soda, a salt which has all the required characters of great solubility, definite form, and the additional pharmaceutic advantage of being readily made into pills, in such a manner as to onsure every pill containing any given fra ${ }^{n+1}$ ion of a grain $w$ is perfect accuracy. Moreover, it may be kept in a crystaline form, and dissolved readily, as it is required. Of the arseniate of soda $I$ have received reports from a great many practitioners, invariably favourable as to its therapeutic effects.

The use of arseniate of soda in medicine is nothing new. It is the basis of Pearson's solution, which consisted of one grain of arseniate of soda to one ounce of water. What the reasons may be which led to this salt having been hitherto omitted from the Pharmacopoia, I am unaware.

About twelve months ago, my attention was particularly directed to the liquor arsenicalis by a physician, who was dissatisfied with its effect, and, at his suggestion, $\mathbb{I}$ was induced to look more closely into this preparation. The directious of the Pharmacopoia for preparing liq. arsenicalis a're as follow:-

"Take of arsenious acid, broken into small pieces, carbonate of potassa, each eighty grains; compound tincture of lavender, five fluid drachms; distilled water, a pint. Boil the arsenious acid and carbonate of potassa with half a pint of the water in a glass vessel until they are dissolved. Add the compound tincture of lavender to the cooled liquor. Lastly, add besides, of distilled water, as much as may be sufficient, that it may accurately fill a pint measure."

I made the following experiment:-

1. Taking 80 grains of arsenious acid in coarse powder, 80 grains of carbonate of potassa, P.L., and 10 ounces of water, 1 found a perfect solution effected on heating, to $212^{\circ}$, with the evolution of only a trace of carbonic acid.

2. The solution was then boiled until it ceased to give off carbonic acid; it required about twenty hours, an equivalent of the carbonate if potassa was decomposed, forming arsenite of potassa, corresponding with the following formula:-

$$
\begin{aligned}
& \mathrm{As} \mathrm{O}_{3} \quad \mathrm{KO}, \mathrm{C} \mathrm{O}_{2}, 1 \frac{1}{2} \mathrm{HO} \quad \mathrm{As} \mathrm{O}_{3} \quad \mathrm{~K} \mathrm{O}, \mathrm{CO}_{2}, 1 \frac{1}{2} \mathrm{HO} \\
& 99: 83.5 \quad: 9^{2} \quad 80^{3}:: 67.5
\end{aligned}
$$

It would appear, therefore, that the liquor arsenicalis of the Pharmacopœia is a solution of arsenious acid in carbonate of potassa, with a minute quantity of arsenite of potassa. On looking through all the dispensatories, and commentaries on the Pharmacopeia, I was surprised to find no allusion to this fact. Soubeiran, however, notices it, but no other French writer on pharmacy sulsequent to Soubeiran, that I arn aware of.

If it be desirable to give arsenions acid with carbonate of potassa, the following process will give a uniform preparation: - Take eighty grains of arsenions acid in coarse powder; eighty grains of carbonate of potassa, P.L.; compound tincture of lavender, five fluid drachms; distilled water sufficient to make up twenty ounces. Boil the arsenious acid in fifteen ounces of water until dissolved, remove it from the fire, allow it to cool a few minutes, and add the carbonate of potassa dissolved in four ounces of cold water; when the temperature of the mixture is reduced to $60^{\circ}$, add the compound tincture of lavender; lastly, make up exactly to twenty ounces with distilled water.

It is probable that many gentlemen may wish to prescribe a true arsenite of potassa, a salt they supposed they were exhibiting in the liq. arsenicalis of the Pharmacopæia. To distinguish this salt from Fowler's solution, it may be called liq. potassæ arsenitis neutralis, and instead of sp. lavand. co., a small quantity of a distilled spirit could be used. The liquor potassæe arsenitis neutralis may be prepared by taking 80 grains of arsenious, and 67.5 grains of carbonate of potassa, P.L., or 81.6 grains of crystalized bicarbonate of potassa. Boil in ten ounces of water until no more carbonic acid is evolved; when cold, make up to exactly twenty ounces, with distilled water, and if thought desirable, a small quantity of a distilled spirit.

There appears to be a variety of opinions as to the best form of giving arsenic. Mr. Hume and others, vide London Medical and Physical Journal, vol. xxiv., would prefer binarseniate of potassa, but $I$ find that this compound, which was admitted into the former edition of the Dublin Pharmacopoeia, has been recently omitted.

The binarseniate of potassa is a beautiful salt easily prepared; keeps well, and from its fine crystaline form its purity is readily ascertained. It would be well if some satisfactory reasons were given for the rejection of this salt.

M. Boudin considers a simple solution of arsenious acid in distilled water as the best; whilst Bieto prefers arseniate of ammonia. There is also a solution of arsenic in some repute, known as De Valangin's solution of solvent mineral, which is a solution of arsenious acid in hydrochloric acid. 
It appears to me that the weight of testimony is in favour of arseniate of soda. M. Cazenar sneaks highly of it; and upon the whole I should say it is proudbry milder in its stion than other forms of arsenic, and, as far as I know, is devoid of objection.

The best method of administering the arseniate of soda is in the form of pills, made up with crumb of bread, or some inert powder.

In conclusion, I think I cannot do better than quote Dr. Powell, who, writing on arsenic, observes, "when the dose is small, and the effect so powerful, the most minute attention to its proportion and preparation becomes necessary."

Conduit-street, Dec. 1850.

\section{A mirror}

OF THE PRACTICE OF

\section{MEDICINE AND SURGERY IN THE \\ HOSPITALS OF LONDON.}

Nuila est alia pro certo noscendi via, nisi quam plurimas et norborum, et aissectionum historias, tum aliorum propras, collectas habere et inter se comparare.-Morgagn. De Sed. et Caus. Morb., lib 14. Proœmium.

\section{ST. BARTHOLOMEW'S HOSPITAL. Diffuse Aneurism.}

(Under the care of Mr. Llord.)

THz wounding of an artery of some size is always an event of a serious character, whether the soft parts have suffered a solution of continuity or not. Indeed, it is principally when the external wound is small, and an artery has been punctured, that the surgeon will have to watch his patient with some care, as the consequences of such a lesion offer certain varieties which will materially infuence the treatment. Nor is the method of treatment either in traumatic, diffuse, or circumscribed aneurism sufficiently settled to render any anxiety unnecessary. Pressure, ice, the ligature at a distance, and the ligature above and below the puncture, have all by turns been advocated, the practitioner having, therefore, to make his choice. A case of diffuse aneurism was lately treated by Mr. Lloyd with the ligature above and below the wound of the ressel; the result was extremely satisfactory, and we beg permission to give a rapid sketch of the case, founded on the notes of Mr. Fletcher, the dresser of the patient.

Thomas J., aged fifteen, a healthy lad, was admitted into Pitcairn's ward, under the care of Mr. Lloyd, November 16 , 1850 , with a tumour occupying the middle third of the inner surface of the right forearm, which latter had in its centre cicatrix, as if from a wound by some sharp instrument. The patient, who is a doll maker, stated, that fourteen days previous to his admission, whilst at work, he accidentally run a sharp narrow-bladed knife to a considerable depth into his forearm. The knife ran directly upwards and backwards, and entered the skin just above the ulna; no pain or hæmorrhage of any importance followed the accident, the boy mentioning that he had lost abont a tea-spoonful of blood. Patient continued at his work, and felt but little inconvenience from the accident, excepting a slight stiffness in the arm. On the eighth day the forearm began to swell, and grow painful, but the distress was not so great as to make him seek for medical relief: he still continued to follow his employment for another week, when it so increased that he was compelled to apply at the hospital.

Upon examination, a tumour was observed of a somewhat oblong form, occupying the middle third of the inner aspect of the right forearm (over the course of the ulnar artery). Its circumference had no defined or indurated margin; the upper part was tense, slightly elastic, but did not present to the touch any signs of fluctuation, and the integuments retained their natural colour. No bruit could then be heard; the radial artery pulsated strongly, the beats of the ulnar were, however, very feeble. There was no pulsation in the tumour, the patient did not complain of any loss of sensation in any of the fingers, nor did the handling of the tumour give him any pain. In the afternoon of the day of the boy's admission, Mr. Lloyd examined the swelling with great care; an indistinct bruit conld now be heard in the tumour, and the latter was likewise influenced by pressure on the brachial artery.
In the evening the bruit became distinctly audible, but no constitutional disturbance had occurred. On the next dar the tumour had manifestly increased, there was greater tension of the surrounding parts; and the diagnosis being now no longer doubtful, Mr. Lloyd determined to tie the ulnar artery above and below the wound of the vessel.

The boy was brought into the theatre on the $17 \mathrm{th}$ of November, the day after admission, and Mr. Lloyd began by making an incision obliquely across the most prominent part of the tumour; this brought into view several soft clots of blood, which were carefully removed. The ulnar artery was now discovered, the vessel presenting a small longitudinal opening, through which blood was slowly oozing. A donble ligature was passed under the artery, the loop cut across, one ligature slipped and tied above the aperture in the vessel, the other below. The patient had been rendered insensible by chloroform; the wound was dressed in the usual way, and the boy removed. His progress was extremely satisfactory; the wound healed very rapidly; there was, during the few first days, slight numbness in the little and ring finger, but this diminished gradually, the wound cicatrized completely, and the patient was discharged, about three weeks after admission. The radial artery pulsated strongly when he left, but the ulnar could not be felt.

Mr. Lloyd, in referring to the tardiness in the collateral circulation to bring the blood into the lower portion of the ulnar artery, mentioned a remarkable case of large tumour in the axilla, which had been under his care some time ago in Bentley ward. The growth invested the nerves and vessels of that region, and was removed, after a very tedious dissection. Five days after the operation, a gush of hremorrhage occurred; this was stopped by pressure, but there was great apprehension of further loss of blood, yet no such accident occurred. The radial and ulnar arteries, however, ceased to pulsate, and these vessels remained quiescent for a twelvemonth, when they again began to answer the systole of the heart. The subject of this latter case was an adult; it is to be supposed that the uluar artery will resume its pulsations in the boy just discharged, long before a year elapses.

It will be noticed that a whole week passed away betweer the puncture of the vessel and the appearance of an y swellin: What took place in the part during that time? According generally received notions, it may be supposed that the track between the aperture of the vessel and the external wound being narrow and irregular, a clot closed the wound made by the pointed instrument, and prevented hæmorrhage; that it became detached, after a week's time, by some effort made with the limb, and that the blood had then gradually insinuated itself into the cellular tissue around, and given rise to diffuse aneurism.

The report states that the swelling increased rapidly, and it may fairly be surmised that the tension would soon have become extreme, the codema considerable, and the limb placed in great jeopardy, if energetic measures had not at once been adopted. Compression in a case like the present is advised by some surgeons, but it is likely that this mode of procedure will have but a very slight influence when the effusion of blood is as considerable as was here noticed. The simplest and safest method is certainly to cut down upon the artery, remove the clots, and tie the vessel above and below the bleeding orifice. It must, however, be clear to those accustomed to operations of this kind that the securing of a vessel under such circumstances is often a very difficult task, as the coagula tend to displace the parts, and change their natural relations; and it is not seldom the case that the congested cellular tissue around the wound of the artery entirely conceals that wound. It has therefore been advised that the vessel should be tied at a distance when the above difficulties are unusually great, or when the search after the artery would give rise to great disturbance of the part. Such is the opinion of Dupuytren. Mr. Guthrie differs from him altogether, and warmly advocates the tying of the vessel above and below its wound, maintaining that the collateral circulation would soon give rise to secondary hæmorrhage from the lower portion of the artery were it left patulons and the vessel tied at a distance. 'There can be no doubt that Mr. Guthrie's method is by far the safest, and it seems particularly applicable to the case we have just reported. There is another mode of dealing with diffuse aneurisms, which we now have an opportunity of seeing employed in a metropolitan hospitalviz., the application of ice. We suspect that the cold is intended to check the progress of the tumour, and change the diffuse into a circumscribed aneurism. We shall watch this latter case with peculiar interest, and offer a report of it as soon as decided results have been obtained. 